\title{
Early on evaluation of hearing function with Transient Evoked Otoacoustic Emissions (TEOAE) and Distortion Product Otoacoustic Emissions (DPOAE) in type 2 diabetic patients without hypertension
}

\author{
Asist Prof. Dr. Oğuz Dikbaş*, Asist Prof. Dr. Tayfun Apuhan**, Asist Prof Dr. Burcu \\ Altunrende***, Asist Prof. Dr. Mesut Erdurmuş****, Asist Prof. Dr. Mehmet Tosun*****, \\ Asist Prof. Dr. Serkan Öztürk****** \\ *Abant Izzet Baysal University School of Medicine Department of Endocrinology and Metabolism \\ **Abant Izzet Baysal University School of Medicine Department of Otorhinolaryngology \\ *** Istanbul Bilim University Europe Florence Nightingale Hospital Research and Training Center Department \\ of Neurology \\ ****Abant Izzet Baysal University School of Medicine Department of Ophtalmology \\ ***** Abant Izzet Baysal University School of Medicine Department of Biochemistry \\ ****** Abant Izzet Baysal University School of Medicine Department of Cardiology
}

Objective: Type 2 diabetes mellitus (DM) is a chronic metabolic disease characterised by insulin resistance and/or reduced insulin secretion from pancreas resulting in disturbance in lipid, protein and carbohydrate metabolism. Elevated blood glucose in patients with diabetes mellitus results in damage to various organs especially eyes, kidneys, nerves, hearth and blood vessels (1). Less well known complication of DM is auditory dysfunction. Sensory neural hearing loss (SNHL) in diabetes mellitus has been described as being bilateral, progressive and seen especially in high frequencies (2). Both TEOAE and DPOAE are generated within the cochlea by the active micromechanisms of the outer hair cells in the organ of corti and gives objective information about the mechanical, preneural components of the peripheral auditory pathway (3). The stimulus used to produce DPOAEs transmits more energy to same specific areas of the cochlea, although stimulus used to achieve TEOAEs is a short duration click whose energy is spread across the whole cochlea. Otoacoustic emission (OAE) testing is accurate, frequency specific, non-invasive and easily applied which specifically reflects the function of the outer hair cells. Altered hearing function in diabetic patients has been found in both pure tone audiometry and OAEs (4). We intended to evaluate the cochlear function with both DPOAE and TEOAE test in patients with DM without polyneuropathy and hypertension.

Patients and Methods: The study was conducted in Otorhinolaryngology and Endocrinology and Metabolism Outpatient Department of Abant Izzet Baysal University Izzet Baysal Research and Training Hospital, Bolu, Turkey. The study group consisted of type 2 diabetic patients and healthy age and sex matched volunteers. Biochemical analysis was done for all patients following overnight fasting. Detailed ear examination, pure tone audiometry, TEOAE, and DPOAE were assessed in all volunteers in sound proof room. Electromyography; so as to exclude cases with polyneuropathy was done in all patients with DM. Also, ophthalmoscopic fundus examination was performed in all diabetic patients.

Results: There are not statistically significant difference between groups according to sex, gender and smoking habits ( $>>0.05$ ). Right ear TEOAE $20 \mathrm{kHz}$ frequency signal to noise ratio $(\mathrm{SNR})(\mathrm{p}=0.043), 40 \mathrm{kHz}$ frequency SNR $(\mathrm{p}=0.018)$ and left ear TEOAE $20 \mathrm{kHz}$ frequency SNR $(\mathrm{P}=0.004)$ are lower in patients with DM (Table-1). Although; there are differences in respective $\mathrm{kHz}$ values between DM and healthy control according to TEOAE test report, there is not statistical significant difference between groups according to overall TEOAE frequencies (left ear $(\mathrm{p}=0.837)$, right ear $(\mathrm{p}=0.442)$ ) (Table-2). There is a statistically significant negative correlation between right ear TEOAE $20 \mathrm{kHz}$ SNR $(\mathrm{P}=0.044)$ and serum glucose level. Also there is a statistically nearly significant negative correlation between right ear TEOAE $40 \mathrm{kHz}$ SNR and retinopathy $(\mathrm{p}=0.053)$. On the other side; there aren't any correlation between duration of diabetes, HbA1c values, TEOAEs and DPOAEs (Table-3). 


\begin{tabular}{|l|l|l|l|}
\hline TEOAE test report & $\begin{array}{l}\text { Diabetes } \\
\text { Mellitus }\end{array}$ & $\begin{array}{l}\text { Healthy } \\
\text { Control }\end{array}$ & $\mathrm{P}$ value \\
\hline Right $10 \mathrm{kHz}$ SNR & 30,90 & 25,58 & $\mathrm{P}=0,220$ \\
\hline Right $14 \mathrm{kHz}$ SNR & 28,54 & 27,55 & $\mathrm{P}=0,819$ \\
\hline Right $20 \mathrm{kHz}$ SNR & 23,22 & 31,98 & $\mathbf{P}=\mathbf{0 , 0 4 3}$ \\
\hline Right $28 \mathrm{kHz}$ SNR & 24,88 & 30,60 & $\mathrm{P}=0,187$ \\
\hline Right $40 \mathrm{kHz}$ SNR & 22,42 & 32,65 & $\mathbf{P}=\mathbf{0 , 0 1 8}$ \\
\hline Left $10 \mathrm{kHz}$ SNR & 28,78 & 27,35 & $\mathrm{P}=0,742$ \\
\hline Left $14 \mathrm{kHz}$ SNR & 29,50 & 26,75 & $\mathrm{P}=0,526$ \\
\hline Left $20 \mathrm{kHz}$ SNR & 21,10 & 33,75 & $\mathbf{P}=\mathbf{0 , 0 0 4}$ \\
\hline Left $28 \mathrm{kHz}$ SNR & 26,58 & 29,18 & $\mathrm{P}=0,548$ \\
\hline Left $40 \mathrm{kHz}$ SNR & 27,64 & 28,30 & $\mathrm{P}=0,879$ \\
\hline
\end{tabular}

Table 1: Comparison of the TEOAEs between DM and Healthy control (Non-parametric Mann-Whitney Test)

\begin{tabular}{|l|l|l|l|l|l|}
\hline & \multicolumn{2}{|l|}{ Diabetes Mellitus } & Healthy Control & P values \\
\cline { 2 - 6 } & Hearing & Not Hearing & Hearing & Not Hearing & \\
\hline DPOAE Right & 18 & 7 & 22 & 8 & \\
\hline DPOAE Left & 14 & 11 & 17 & 13 & $\mathrm{P}=0,913$ \\
\hline TEOAE Right & 15 & 10 & 21 & 9 & $\mathrm{P}=0,961$ \\
\hline TEOAE Left & 16 & 9 & 20 & 10 & $\mathrm{P}=0,442$ \\
\hline
\end{tabular}

Table 2: Cochlear function according to overall TEOAE frequencies between DM and healthy control was shown. (Non-parametric Mann-Whitney Test)

\begin{tabular}{|l|l|l|l|l|}
\hline & Glucose & HbA1c & Retinopathy & Duration of Diabetes \\
\hline TEOAE Right 20 kHz & $\mathrm{r}=-0,273$ & $\mathrm{r}=-0,119$ & $\mathrm{r}=-0,375$ & $\mathrm{r}=0,010$ \\
SNR & $\mathbf{p}=\mathbf{0 , 0 4 4} *$ & $\mathrm{p}=0,608$ & $\mathrm{p}=0,064$ & $\mathrm{p}=0,963$ \\
\hline TEOAE Right 40 kHz & $\mathrm{r}=-0,157$ & $\mathrm{r}=-0,64$ & $\mathrm{r}=-0,391$ & $\mathrm{r}=-0,28$ \\
SNR & $\mathrm{p}=0,254$ & $\mathrm{p}=0,782$ & $\mathbf{p}=\mathbf{0 , 0 5 3} * *$ & $\mathrm{p}=0,895$ \\
\hline TEOAE Left $20 \mathrm{kHz}$ & $\mathrm{r}=-0,240$ & $\mathrm{r}=-0,250$ & $\mathrm{r}=-0,283$ & $\mathrm{r}=-0,017$ \\
SNR & $\mathrm{p}=0,078$ & $\mathrm{p}=0,275$ & $\mathrm{p}=0,171$ & $\mathrm{p}=0,934$ \\
\hline
\end{tabular}

Table-3: Correlation analysis of glucose, $\mathrm{HbA} 1 \mathrm{c}$, retinopathy and duration of diabetes with TEOAE frequencies (Pearson's Correlation analysis)

*Statistically significant

**Statistically nearly significant

Conclusion: This study was done to evaluate cochlear function in electromyography test negative, nonalcoholic and normotensive type 2 DM patients. There are a lot of study in the literature that was performed with TEOAE and/or DPOAE. All of these studies uncovered the detrimental effect of DM on cochlear function (4-6). Besides this, according to our datas: TEOAE measurements at some frequencies were significantly reduced in patients with DM. 
Considering overall frequencies, meaningful reduction of cochlear function was not observed. This suggests us that in patients with DM, cochlear function was not affected.

\section{References:}

1-American Diabetes Association. Diagnosis and classification of diabetes mellitus. Diabetes Care 2010; 33: S62-S69

2-Parving A, Elberling C, Balle V, Parbo J, Dejgaard A, Parving H. Hearing disorders in patients with insulin-dependent diabetes mellitus. Audiology 1990; 29: 113-121

3-Kemp DT. Stimulated acoustic emissions from within the human auditory system. J Acoust Soc Am. 1978; 64:1386-1391

4-Pessin ABB, Martins RHG, Pimenta WDP, Simoes ACP, Marsiglia A, Amaral AV.

Auditory evaluation in patients with type 1 diabetes. Ann Otol Rhinol Laryngol 2008; 117:

366-370

5-Díaz de León-Morales LV, Jáuregui-Renaud K, Garay-Sevilla ME, Hernández-Prado J,

Malacara-Hernández JM. Auditory impairment in patients with type 2 diabetes mellitus. Arch Med Res. 2005; 36 (5): 507-510

6-Lisowska G, Namyslowski G, Morawski K, Strojek K. Otoacoustic emissions and auditory brain stem responses in insulin dependent diabetic patients. Otolaryngol Pol. 2002; 56(2):

217-25 